\title{
A DEFORMATION MECHANISM MAP OF ICE
}

\author{
By H. Shōji and A. Higashi
}

(Department of Applied Physics, Faculty of Engineering, Hokkaido University, Sapporo, Japan o6o)

ABSTRACT. A deformation mechanism map for pure polycrystalline ice of $2 \mathrm{~mm}$ grain diameter is con-
structed. New sub-regions in the dislocation glide region are proposed: dislocation glide with crack formation,
dislocation creep, and fracture at high stresses above about $\mathrm{I}$ MPa. The boundary between the dislocation
creep and DGC regions is determined by the onset of cleavage cracks due to piled-up dislocations near grain
boundaries. The fracture region is that area of the map where fracture occurs readily when the ice is sub-
jected to a rapid deformation rate exceeding $10^{-3} \mathrm{~s}^{-1}$. Experimental results of the stress dependence of the
compressive deformation rate of polycrystalline ice are compared with the map. The effect of changes in the
creep activation energy near the melting point is discussed together with those of other factors.

RÉsumé. Carte des mécanismes de déformation de la glace. Une carte des mécanismes de déformation correspondant à une glace polycristalline (diamètre des grains $2 \mathrm{~mm}$ ) est construite. Nous proposons de considérer plusieurs sous-domaines dans le domaine attribué au glissement des dislocations: au-dessus du fluage par glissement de dislocations, il y aurait mouvement de dislocations avec formation de fissure (DGC) et fracture pour des contraintes élevées au-dessus de I MPa environ. La frontière entre les sous-domaines fluage et DGC est assimilée au critère de début de formation de fissure par empilement de dislocations vers les joints de grain. Le sous-domaine relatif à la fracture est établi à partir de données expérimentales montrant que la rupture fragile se produit à coup sûr quand la glace est déformée à une vitesse élevée, dépassant ${ }^{10^{-3}} \mathrm{~s}^{-1}$. Divers résultats expérimentaux concernant la relation entre contrainte et vitesse de déformation en compression de glaces polycristallines sont comparés aux indications de notre carte. Les effets de la variation de l'énergie d'activation du fluage vers le point de fusion sont discutés en relation avec divers autres facteurs.

Zusammenfassung. Ein Verformungsmechanismus-Diagramm für Eis. Für reines, polykristallines Eis mit $2 \mathrm{~mm}$ Korndurchmesser wird ein Verformungsmechanismus-Diagramm ausgearbeitet. Es werden neue Unterfelder in dem Feld der Versetzungsgleitung vorgeschlagen: Versetzungsgleitung mit Spaltenbildung (DGC), Versetzungskriechen und Bruch bei hohen Spannungen oberhalb von ungefähr I MPa. Die Grenze zwischen Versetzungskriechen und DGC wird durch das Auftreten von Spaltungsrissen infolge aufgehäufter Versetzungen in der Nähe von Korngrenzen bestimmt. Das Bruchfeld ist die Fläche des Diagramms, in der Bruch sofort eintritt, wenn das Eis einer schnellen Verformung mit Geschwindigkeiten $>\mathrm{IO}^{-3} \mathrm{~s}^{-1}$ unterworfen wird. Ergebnisse Experimentelle der Spannungsabhängigkeit der Kompressionsverformungsgeschwindigkeit polykristallinen Eises werden mit dem Diagramm verglichen. Die Auswirkung der Änderung der Aktivierungsenergie der Kriechgeschwindigkeit nahe dem Schmelzpunkt wird zusammen mit den Auswirkungen anderer Faktoren besprochen.

\section{InTRODUCTION}

The deformation map of ice should, as with other materials, prove useful in summarizing the deformation behaviour of polycrystalline ice at various temperatures and stress levels. However, the complete map for ice has not yet been constructed due to a lack of established equations for some of the mechanisms. Goodman and others (1977) proposed the first maps for pure ice and for ice containing 3 p.p.m. of HF. Equations used for determining the dislocation glide field were derived from new concepts of the proton rearrangement which controls the velocity of dislocations in ice (Whitworth and others, 1976; Frost and others, 1976). They concluded from comparisons of the maps with those of other materials that ice is remarkably stronger than other substances for a given homologous temperature and normalized stress.

In our studies on mechanical properties of well-oriented deep core ice from Antarctica (Higashi and Shōji, I974), we found that polycrystalline ice tended to fracture at a constant resolved shear stress of approximately 2-4 bar. With randomly-oriented, artificially-grown polycrystalline ice, many investigators reported that the first crack in compressive tests appeared at stresses of a few bar. Therefore, above this stress, we should introduce a field in which the deformation takes place by dislocation glide accompanied by ductile fracture caused by dislocation pile-ups at grain boundaries.

On the other hand, it is also observed by many investigators that polycrystalline ice fractures readily when it is subjected to a rapid deformation rate exceeding $1 \mathrm{O}^{-3} \mathrm{~s}^{-1}$. Then, 
the upper part of the region of dislocation glide should be subdivided to include a fracture region for practical usage of the map. In consequence, the area which has been hitherto described as the dislocation glide region can be divided into three subfields: dislocation creep, dislocation glide with crack formation (abbreviated as DGC hereafter), and fracture, depending on the stress level.

Constitutive equations for determining the extent of the DGC sub-region are derived from the assumption that the ductile cleavage fracture occurs as a result of pile-up of dislocations, but the numerical constants are determined from experimental data. Our approach for the construction of the map is, therefore, semi-empirical.

The results of computations are expressed on a map of the usual type, the homologous temperature on the abscissa, and the normalized shear stress on the ordinate, with contours of constant strain-rate. Extrinsic conditions specified with the material on the map are that individual grains in polycrystalline ice are randomly oriented and the mean grain diameter is $2 \mathrm{~mm}$.

\section{Constitutive equations}

For expressing the flow law of ice to be inserted in the deformation map, we adopted the effective strain rate $\dot{\epsilon}=\left(\frac{1}{2} \dot{\epsilon}_{i j} \dot{\epsilon}_{i j}\right)^{\frac{1}{2}}$ and the effective shear stress $\tau=\left(\frac{1}{2} \sigma_{i j}{ }^{\prime} \sigma_{i j}{ }^{\prime}\right)^{\frac{1}{2}}$ as was proposed by Nye (1957). Here, $\sigma_{i j}{ }^{\prime}$ is the stress deviator expressed as $\sigma_{i j}{ }^{\prime}=\sigma_{i j}-\frac{1}{3} \delta_{i j} \sigma_{i j}$. If the equivalent shear strain-rate $\dot{\gamma}$ is adopted as Goodman and others (I977) did recently, it should be twice our effective strain-rate $\dot{\epsilon}$. This would not make much difference in the construction of constant strain-rate curves on the map.

\subsection{Diffusional creep}

At very low stresses, ice deforms by the diffusion mechanism like other materials. Depending on the diffusion path there are two different processes: One is called the lattice diffusion mechanism which is the flow of point defects through bulk grains, and another is the boundary diffusion mechanism which is caused by the flow of point defects through grain boundaries. Their constitutive equations are respectively given by (Herring, I950; Coble, 1963; Raj and Ashby, r97 I):

$$
\begin{gathered}
\dot{\epsilon}_{1}=2 \mathrm{I}(\tau \Omega / k T)\left(D_{1} / d^{2}\right), \quad D_{1}=D_{\mathrm{l}_{0}} \exp (-Q / R T), \\
\text { (lattice diffusion mechanism) } \\
\dot{\epsilon}_{\mathrm{b}}=2 \mathrm{I} \pi(\tau \Omega / k T)\left(\delta D_{\mathrm{b}} / d^{3}\right), \quad D_{\mathrm{b}}=D_{\mathrm{b}_{\mathrm{o}}} \exp \left(-Q_{\mathrm{b}} / R T\right) . \\
\text { (boundary diffusion mechanism) }
\end{gathered}
$$

The meaning of letters in the equations are explained in Table I.

\section{TABle I. Nomenclature and numerical values}

$\begin{array}{cl}G & \text { Shear modulus } \\ \Omega & \text { Atomic volume } \\ k & \text { Boltzman's constant } \\ D_{\mathrm{l}_{\mathrm{o}}} & \text { Pre-exponential term for lattice diffusion coefficient } \\ D_{\mathrm{b}_{\mathrm{o}}} & \text { Pre-exponential term for boundary diffusion coefficient } \\ Q & \text { Activation energy for lattice diffusion coefficient } \\ Q_{\mathrm{b}} & \text { Activation energy for boundary diffusion coefficient assumed as } \frac{2}{3} \text { of } Q \\ Q_{\mathrm{d}} & \text { Activation energy for dislocation creep } \\ Q^{\prime} & \text { (adopted for high temperature region as above }{ }^{26} 6_{5} \mathrm{~K} \text { ) } \\ \gamma_{\mathrm{s}} & \text { Activation energy for the movement of a single dislocation in ice } \\ d & \text { Grain diameter } \\ b & \text { Burger's vector of dislocations on the basal plane of ice } \\ \nu & \text { Poisson's ratio } \\ \delta & \text { Effective width of grain boundary }\end{array}$

$3.0 \times 10^{3} \mathrm{MPa}$
$3.27 \times 10^{-29} \mathrm{~m}^{3}$
$1.38 \times 10^{-23} \mathrm{~J} / \mathrm{K}$
$3.0 \times 10^{-2} \mathrm{~m}^{2} / \mathrm{s}$
$3.0 \times 10^{-2} \mathrm{~m}^{2} / \mathrm{s}$
$66.2 \mathrm{~kJ} / \mathrm{mol}^{2}$
$46.1 \mathrm{~kJ} / \mathrm{mol}$
$66.2 \mathrm{~kJ} / \mathrm{mol}$
$126 \mathrm{~kJ} / \mathrm{mol}$
$52.4 \mathrm{~kJ} / \mathrm{mol}$
$1 \times 10^{-1} \mathrm{~J} / \mathrm{m}^{2}$
$2 \times 10^{-3} \mathrm{~m}$
$4.5 \times 10^{-10} \mathrm{~m}$
0.3
$2 b$


The linear stress dependence of the strain-rate is included in both lattice and boundary diffusion. If we assume that the activation energy for boundary diffusion $Q_{\mathbf{b}}$ is much less than that for lattice diffusion, as is the case in metals, the boundary diffusion mechanism is dominant only at low temperatures. Disposition of the crossover between two mechanisms depends upon the estimate of $Q_{\mathbf{b}} / Q$ and its actual method of evaluation is given in Section 3 .

\subsection{Dislocation creep}

At temperatures above about $0.5 T_{m}\left(T_{m}\right.$ is the melting temperature in $\left.\mathrm{K}\right)$ and under relatively higher stresses than those at which diffusional creep prevails (approximately $\mathrm{IO}^{-2} \mathrm{MPa}$ ), the dislocation creep mechanism is dominant. The constitutive equation for this mechanism may be properly derived from a consideration of the factors which control dislocation velocity as proposed by Goodman and others (1977). However, we adopt here the third-power law which is generally accepted from many experimental results. Then, the constitutive equation for this region is:

$$
\dot{\epsilon}_{\mathrm{dc}}=A \tau^{3} \exp \left(-Q_{\mathrm{d}} / R T\right) .
$$

The activation energy $Q_{\mathrm{d}}$ is known to be $66.2 \mathrm{~kJ} / \mathrm{mol}$ below $265 \mathrm{~K}$ but to increase abruptly above $263 \mathrm{~K}$ to the melting point (Barnes and others, 197I). In constructing the present map, $Q_{\mathrm{d}}$ was taken as $126 \mathrm{~kJ} / \mathrm{mol}$ at temperatures above $265 \mathrm{~K}$.

\subsection{Onset of cleavage crack}

The onset of cleavage cracks, that is, the propagation of cracks from the piled-up dislocations near the boundaries takes place at a critical stress given by (Petch, 1969):

$$
\sigma=4 \gamma_{\mathrm{s}} G / k_{f} d^{\frac{1}{2}} \text {. }
$$

In this equation, $\gamma_{\mathrm{s}}$ is the surface energy of the crystal, $G$ the modulus of rigidity, $d$ the grain diameter, and $k_{f}$ is a constant. This equation is derived from the assumption that the work done on the number of dislocations piled-up is transferred to the internal surface energy of a cleavage crack. The constant $k_{f}$ is given by

$$
k_{f}={ }_{2} G[b / 2 \pi(\mathbf{I}-\nu)]^{\frac{1}{2}},
$$

when the pile-up of dislocations occurs only on one primary slip plane, as in the case of ice (Stroh, 1957).

When a cleavage crack is formed, many secondary dislocations appear around the crack to release the large strain at or around its tip. Thus we must consider an additional energy $\gamma_{p}$ in addition to the internal surface energy $\gamma_{\mathrm{s}}$. As stated in the Appendix, $\gamma_{p}$ may be expressed to a good approximation as,

$$
\gamma_{p}=B V_{\mathbf{d}},
$$

where $V_{\mathrm{d}}$ is the velocity of dislocations under stress and $B$ is a constant to be determined from experimental data. Then, rewriting Equation (4), the critical shear stress for the start of cleavage-crack propagation is given as

$$
\tau_{\mathrm{c}}=(4 / \sqrt{ } 3)\left[G\left(\gamma_{\mathrm{s}}+B V_{\mathrm{d}}\right)\right] / k_{f} d^{\frac{1}{2}} .
$$

Since $V_{\mathbf{d}}$ is proportional to the applied shear stress (Fukuda and Higashi, r973) and its temperature dependence should be of the Arrhenius type:

$$
V_{\mathbf{d}}=V_{0} \tau \exp \left(-Q^{\prime} / R T\right),
$$

where $V_{0}$ is the velocity at a standard stress and temperature. The value of the activation 
energy $Q^{\prime}$ calculated from the data of Maï (1976) is a little less than that for creep $\left(5^{2.4}\right.$ $\mathrm{kJ} \mathrm{mol}^{-1}$ ). Insertion of Equation (8) into Equation (7) gives an intrinsic expression for the temperature dependence of $\tau_{\mathrm{e}}$, but it may be converted to

$$
\tau_{\mathrm{c}}=4 \gamma_{\mathrm{s}} /\left(2 \sqrt{ } 3[b d / 2(\mathrm{I}-\nu)]^{\frac{1}{2}}-4 B V_{0} \exp \left(-Q^{\prime} / R T\right)\right) .
$$

This is an equation which can be used to give the criterion for the onset of cleavage crack or used for drawing the boundary between the dislocation creep and DGC regions on a deformation map.

\subsection{Dislocation glide with cracks}

The stress at which cracks first appeared in specimens of polycrystalline ice in the deformation process was reported by several investigators. Hawkes and Mellor (1972) reported the stress to be $2-4 \mathrm{MPa}$ at $266 \mathrm{~K}$, and Gold (1972) made the observation of $0.6 \mathrm{MPa}$ at 242-268 K. Parameswaran and Jones (1975) reported the value of $0 . \mathrm{I}-0.5 \mathrm{MPa}$ at the very low temperature of $77 \mathrm{~K}$. Therefore, polycrystalline ice subjected to stresses above a few bars should almost certainly include cleavage cracks and these should influence the deformation behaviour of the ice. Our experiments with Antarctic core ice which already includes many cracks or air bubbles showed that this ice deformed faster than laboratorygrown ice even at the lower stress level which would correspond to the dislocation creep region of the map, although the stress dependence of the strain-rate $\left(\tau^{3}\right)$ did not change. This softening effect of the cracks can be understood as a result of increased numbers of dislocations generated from the crack surface. When polycrystalline ice is subjected to stresses above a few bars, the number and size of cracks increase with increasing stress and time.

We can assume that the strain-rate $\dot{\epsilon}_{\mathrm{DGC}}$ in the DGG region takes the form

$$
\dot{\epsilon}_{\mathrm{DGC}}=K^{\prime} S \dot{\epsilon}_{\mathrm{dc}},
$$

where $K^{\prime}$ is a constant and $S$ is the total surface area of cracks. At low stresses, $S$ is constant for ice specimens containing some cracks, but at higher stress $S$ varies with $\tau$ in the way described below. If the cracks are to be formed by dislocation pile-ups near grain boundaries as Stroh proposed, the number of cracks, and therefore $S$, should be proportional to the mobile dislocation density which is equal to $\dot{\epsilon}_{\mathrm{dc}} / b V_{\mathrm{d}}{ }^{\prime}$ from Orowan's relation. Generation and pile-up of such mobile dislocations in individual grains may be controlled by the structure of boundaries surrounding grains. $V_{\mathrm{d}}{ }^{\prime}$ is the average velocity of dislocations in grains of polycrystalline ice and it should be proportional to the velocity of a single dislocation $V_{\mathrm{d}}$. Considering that $\dot{\epsilon}_{\text {de }}$ is proportional to $\tau^{3}$ and $V_{\mathrm{d}}$ to $\tau$, we obtain from Equations (8) and (Io) the following relation,

$$
\dot{\epsilon}_{\mathrm{DGC}}=K \tau^{5} \exp \left(-Q^{\prime} \mid R T\right),
$$

where $K$ is a constant which is to be determined from the experimental data. The flow rate in the DGC region is dependent on $\tau^{5}$.

In the low temperature $\left(<0.7 T_{m}\right)$ area of the DGC region, the total strain-rate may be largely controlled by cracking itself. In this area, the motion of dislocations does not play a role in glide but is only involved in nucleating cracks according to Stroh's model. Here, the constitutive equation may be written as

$$
\dot{\epsilon}_{\mathrm{c}}=\mathcal{N h} V_{\mathrm{c}},
$$

where $\mathcal{N}$ is the crack density and $h$ is the thickness of a crack. Since $V_{\mathrm{c}}$ should be strongly stress dependent but weakly temperature dependent, the contours of equal strain-rate may tend to be parallel to the abscissa. However, no quantitative calculation was carried out for this region. 


\subsection{Fracture region and ideal strength}

The fracture region is based on the experimental observation that polycrystalline ice fractures readily when it is subjected to a rapid deformation at a rate exceeding $\mathrm{IO}^{-3} \mathrm{~s}^{-1}$. No constitutive equation is given for this region. Methods of drawing the boundary between this and the DGC region will be given in Section 3 .

At higher stresses above the ideal strength $\tau_{t}$, the crystal can deform without the need for any defect. Since $\tau_{t}$ is of the order of o.I $G$, the strain-rate is infinite at stresses greater than this value.

\section{Construction of a map}

A deformation mechanism map of ice has been constructed using the principles outlined in the preceding Sections and it is shown in Figure $\mathrm{I}$. The region boundaries are drawn by equating pairs of the constitutive equations and solving for the stress as a function of temperature. Boundaries between the diffusion (lattice and boundary) creep regions and the dislocation creep region are obtained by equating each of Equations (I) and (2) with Equation (3). The dividing line between the lattice- and boundary-diffusion creep is determined by assuming that the ratio $Q_{\mathrm{b}} / Q=\frac{2}{3}$ and $Q_{\mathrm{b}_{0}}=Q_{\mathrm{1}_{0}}$.

Three sub-regions, dislocation creep, DGC, and fracture are distinguished by determining the positions of boundaries given by Equation (9) and the limiting conditions stated in Section 2.5. For the actual position of the boundary between dislocation creep and the DGG, we need to determine the numerical value of $B$ in Equation (9). This was carried out using the data of Hawkes and Mellor (1972); $\tau_{\mathrm{c}}=2 \mathrm{MPa}$ at a temperature of $266 \mathrm{~K}$ in Equation (9). Then, the boundary, which runs from this datum point steeply downwards with decreasing temperature and which flattens off below $0.8 T_{m}$, was obtained by calculating

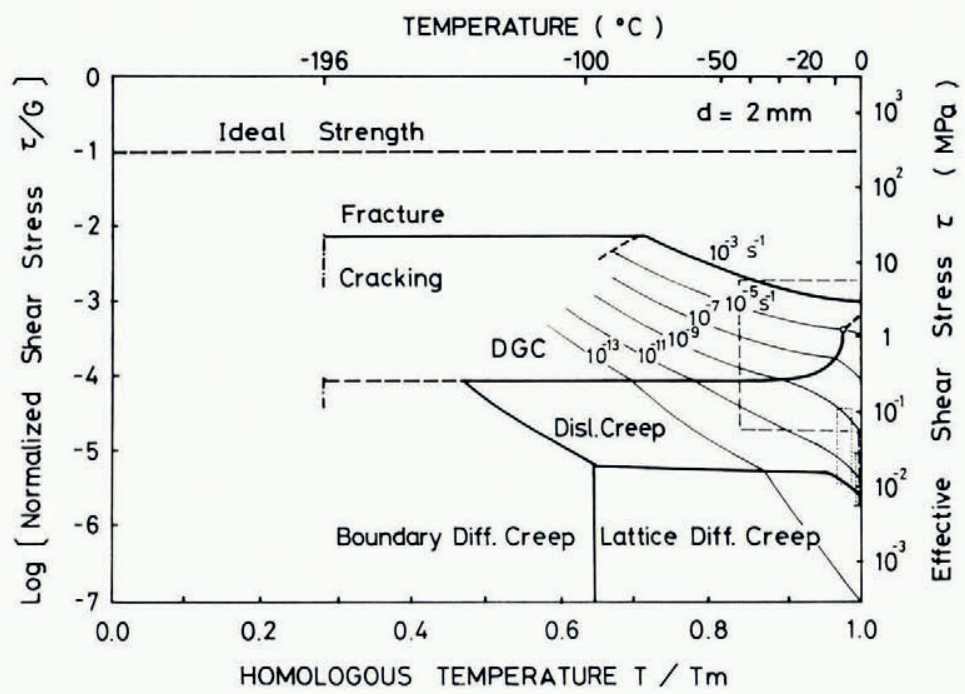

Fig. I. A deformation mechanism map for pure ice of grain size $2 \mathrm{~mm}$. Experimental data are also shown on the map as follows:

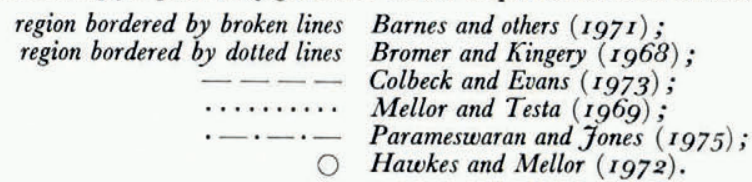


$\tau_{\mathrm{c}}$ using Equation (9). This boundary coincides well with the observed data of Parameswaran and Jones (1975) at $77 \mathrm{~K}$.

In order to draw the equal strain-rate contours in the DGC region based on Equation (I I), a numerical value for $K$ must be determined. It is fixed so that the value of $\dot{\epsilon}$ determined by Equation (I I) is equal to that of $\dot{\epsilon}$ given by Equation (3) at the boundary between the dislocation creep and DGG region. Several contours from $10^{-13} \mathrm{~s}^{-1}$ to $10^{-3} \mathrm{~s}^{-1}$ are shown on the map.

The boundary between DGC and fracture is drawn on the $10^{-3} \mathrm{~s}^{-1}$ contour line in a relatively high-temperature region. In the low-temperature region below $0.7 T_{m}$, the boundary is drawn parallel to the abscissa from the point at which Parameswaran and Jones (1975) observed sudden fracture for reasons stated in Section 2.4.

\section{Discussion}

\section{I. Stress dependence}

In the high temperature $\left(>0.6 T_{m}\right)$ range of the proposed map, the stress exponent $n$ in the dependence of strain-rate on stress increases from one (diffusion creep), through three (dislocation creep) to five (DGC) with increasing stress. This increasing stress dependence agrees well with experimental data previously obtained for the flow law of ice. The data are restricted to a comparatively narrow area on the map in both stress and temperature ranges. Available data are plotted on the map by squares or lines as indicated in the legends. Bromer and Kingery (1968) found $n$ to be one in an area of effective shear stress from $1.2 \times 10^{-2} \mathrm{MPa}$ to $1.2 \times 10^{-1} \mathrm{MPa}$ and for temperatures between $260 \mathrm{~K}$ and $270 \mathrm{~K}$. Mellor and Testa (1969) found $n$ to be $\mathrm{I} .8$ at effective shear stresses from $5.8 \times 10^{-3} \mathrm{MPa}$ to $2.9 \times 10^{-2} \mathrm{MPa}$ and at a temperature of $27 \mathrm{r} \mathrm{K}$. These data do not agree well with the regions of the map. Colbeck and Evans (1973) examined the creep data of glacier ice at effective shear stresses between $3.5 \times 10^{-3} \mathrm{MPa}$ and $5.8 \times 10^{-2} \mathrm{MPa}$ at the pressure-melting point and proposed a polynomial flow law containing linear, cubic, and fifth-power stress terms. This expression indicates that a linear term is dominant at low stresses and the cubic and fifth-power terms dominate with increasing stress. Barnes and others (I97I) found $n$ to be three in a wide range of stresses from $5.8 \times 10^{-2} \mathrm{MPa}$ to $5.8 \mathrm{MPa}$ and temperatures from $225 \mathrm{~K}$ to $27 \mathrm{I} \mathrm{K}$. At low stresses, their data suggest that stress exponent $n$ is indeed three, but there is a tendency for it to increase to five at higher stresses (near $5.8 \mathrm{MPa}$ ).

\subsection{Activation energy}

It has been reported that the activation energy for the creep of ice at high temperatures near to the melting point (above approximately $265 \mathrm{~K}$ ) is much higher than that at a lower temperature, that is to say almost twice as high as the normal activation energy. If this is considered, then a bend appears on any boundary between different fields near the ordinate at $T_{m}$ as shown by the dotted line on the boundary between dislocation creep and DGC. Another example of this is the bend downwards from the horizontal boundary between lattice-diffusion creep and dislocation creep. At higher stress above ro MPa, we should incorporate a pressure-melting region in the map but it is not shown in this diagram.

\subsection{Hydrostatic pressure}

Our recent experiments (Higashi and Shōji, I974 and unpublished data) on the deformation behaviour of deep Antarctic core ice under hydrostatic pressure revealed that the strainrate decreases with increasing pressure while the fracture stress increases. This effect must be caused by the closure of cracks under hydrostatic pressure and it is expected that the line of onset of cleavage cracking or the boundary between dislocation creep and DGG will be 
shifted upward to higher stress levels on the map and the dislocation creep region will be expanded. This effect should be taken into consideration when we wish to apply the map to our understanding of ice flow within glaciers or ice sheets.

The effects of other factors such as grain size and the distribution of $c$-axis orientations must be considered in a practical use of the map. Grain-size changes affect the region of diffusion creep and the boundary between the dislocation creep and DGC regions as predicted by Equations (I), (2), and (9). Finally, it should be emphasized that the map proposed here was constructed for uniaxial compressive stress without any superimposed hydrostatic pressure.

\section{REFERENCES}

Barnes, P., and others. I97I. The friction and creep of polycrystalline ice, by P. Barnes, D. Tabor and J. C. F. Walker. Proceedings of the Royal Society of London, Ser. A, Vol. 324, No. 1557, p. 127-55.

Bromer, D. J., and Kingery, W. D. 1968. Flow of polycrystalline ice at low stresses and small strains. Fournal of Applied Physics, Vol. 39, No. 3, p. 1688-91.

Coble, R. L. ${ }^{1} 963$. A model for boundary diffusion controlled creep in polycrystalline materials. Fournal of Applied Physics, Vol. 34, No. 6, p. $1679-82$.

Colbeck, S. C., and Evans, R. J. 1973. A flow law for temperate glacier ice. Journal of Glaciology, Vol. 12, No. 64, p. $7 \mathrm{I}-86$.

Frost, H. J., and others. 1976. Kink velocities on dislocations in ice. A comment on the Whitworth, Paren and Glen model, by H. J. Frost, D. J. Goodman and M. F. Ashby. Philosophical Magazine, Eighth Ser., Vol. 33 , No. 6, p. $95^{\mathrm{I}-6 \mathrm{I}}$.

Fukuda, A., and Higashi, A. 1973. Dynamical behavior of dislocation in ice crystals. Crystal Lattice Defects, Vol. 4, No. 3, p. 203-10.

Gold, L. W. 1972. The process of failures of columnar-grained ice. Philosophical Magazine, Eighth Ser., Vol. 26, No. 2, p. $311-28$.

Goodman, D. J., and others. 1977. The effect of impurities on the creep of ice $I_{h}$ and its illustration by the construction of deformation maps, [by] D. J. Goodman, H. J. Frost and M. F. Ashby. [Union Géodésique et Géophysique Internationale. Association Internationale des Sciences Hydrologiques. Commission des Neiges et Glaces.] Symposium. Isotopes et impuretés dans les neiges et glaces. Actes du colloque de Grenoble, août/septembre 1975, p. 17-22. (IAHS-AIHS Publication No. 118 .)

Hawkes, I., and Mellor, M. 1972. Deformation and fracture of ice under uniaxial stress. Fournal of Glaciology, Vol. 1 I, No. 6r, p. 103-31.

Herring, C. I950. Diffusional viscosity of a polycrystalline solid. Journal of Applied Physics, Vol. 21, No. 5, p. $437-45$.

Higashi, A. r 974 . Growth and perfection of ice crystals. Fournal of Crystal Growth, Vol. 24-25, p. 102-07.

Higashi, A., and Shōji, H. 1974. Nankyoku hyōshō shinbuhyō no rikigakuteki seishitsu [Mechanical properties of deep ice core samples obtained at "Byrd" station, Antarctica]. (In Kuroiwa, D., ed. Kyokuchi hyōshōhyō no butsuriteki kagakuteki kenkyū [Physical and chemical studies on ices from glaciers and ice sheets]. Monbushō Kagaku Kenpi Sōgō Kenkyū (A). Hōkokusho, [1973,] p. I-13.)

Maï, C. 1976. Étude par topographie $\mathrm{X}$ du comportement dynamique des dislocations dans la glace Ih. Comptes Rendus Hebdomadaires des Séances de l'Académie des Sciences (Paris), Sér. B, Tom. 282, No. 22, p. 515-18.

Mellor, M., and Testa, R. 1969. Creep of ice under low stress. Fournal of Glaciology, Vol. 8, No. 52, p. ${ }^{2} 47-52$.

Nye, J. F. 1957. The distribution of stress and velocity in glaciers and ice-sheets. Proceedings of the Royal Society of London, Ser. A, Vol. 239, No. 1216, p. $113-33$.

Orowan, E. [ [ $\left.{ }^{\mathrm{C}} \mathrm{I} 952.\right]$ Fundamentals of brittle behavior in metals. (In Murray, W. M., ed. Fatigue and fracture of metals. A symposium held at the Massachusetts Institute of Technology, June 19-22, 1950. [Cambridge, Mass.], M.I.T. Press; New York, John Wiley and Sons, p. 139-67.)

Parameswaran, V. R., and Jones, S. J. 1975. Brittle fracture of ice at 77 K. Journal of Glaciology, Vol. 14, No. 71, p. $305^{-1} 5$.

Petch, M. J. 1969. Metallographic aspects of fracture. (In Liebowitz, H., ed. Fracture: an advanced treatise. Vol. 1. Microscopic and macroscopic fundamentals. New York, Academic Press, p. 351-93.)

Raj, R., and Ashby, M. F. I97ı. On grain boundary sliding and diffusional creep. Metallurgical Transactions Vol. 2, No. 4, p. $1113-27$.

Stroh, A. 1957. A theory of fracture of metals. Advances in Physics, Vol. 6, No. 24, p. 418-65.

Tetelman, A. S. [ $\left.{ }^{\mathrm{C}} \mathrm{r} 963.\right]$ The plastic deformation at the tip of a moving crack. (In Druker, D. C., and Gilman, J. J., ed. Fracture of solids. Proceedings of an international conference ... . [held in] Maple Valley, Washington, August $2 I-24,1962$. New York, Interscience Division of John Wiley and Sons, p. $46 \mathrm{r}-50 \mathrm{r}$. (Metallurgical Society Conferences, Vol. 20.))

Whitworth, R. W., and others. 1976. The velocity of dislocations in ice-a theory based on proton disorder, by R. W. Whitworth, J. G. Paren and J. W. Glen. Philosophical Magazine, Eighth Ser., Vol. 33, No. 3, p. 409-26. 


\section{APPENDIX}

\section{VERIFICATION OF $\gamma_{p}=B V_{\mathbf{d}}$}

Strain fields formed around a crack generated by compressive stresses in an ice single crystal were examined using X-ray diffraction topography. The single crystal was grown by the modified Bridgman method (Higashi, 1974) and its original dislocation density was $10^{2} \mathrm{~cm}^{-2}$. When a thin specimen of the crystal was compressed, two characteristic dislocation mages appear on a topograph taken with a $\langle 11 \overline{2} 0\rangle$ g-vector with scanning on the (OOOI) plane (Fig. AI (a)). One image consists of straight lines extended along three $\langle\mathbf{I} \overline{2} \mathbf{2}\rangle$ directions which are commonly observed in deformed ice single crystals (Fukuda and Higashi, 1973). Another type of image is a dense, complicated one associated with dislocations around the crack. Since the dislocations are distributed widely around the crack, as illustrated in Figure $\mathrm{A}_{\mathrm{I}}(\mathrm{b})$, they seem to be generated from free surfaces of the sample, not at the tip of the crack. It is conceivable that such bundles of dislocations help to relax stress concentrations near the tip and even prevent propagation of the crack, as proposed by Tetelman $\left[{ }^{\mathrm{c}}{ }_{196} 6_{3}\right.$. In the case of polycrystalline ice, such bundles of dislocations might be generated from grain boundaries instead of free surfaces.
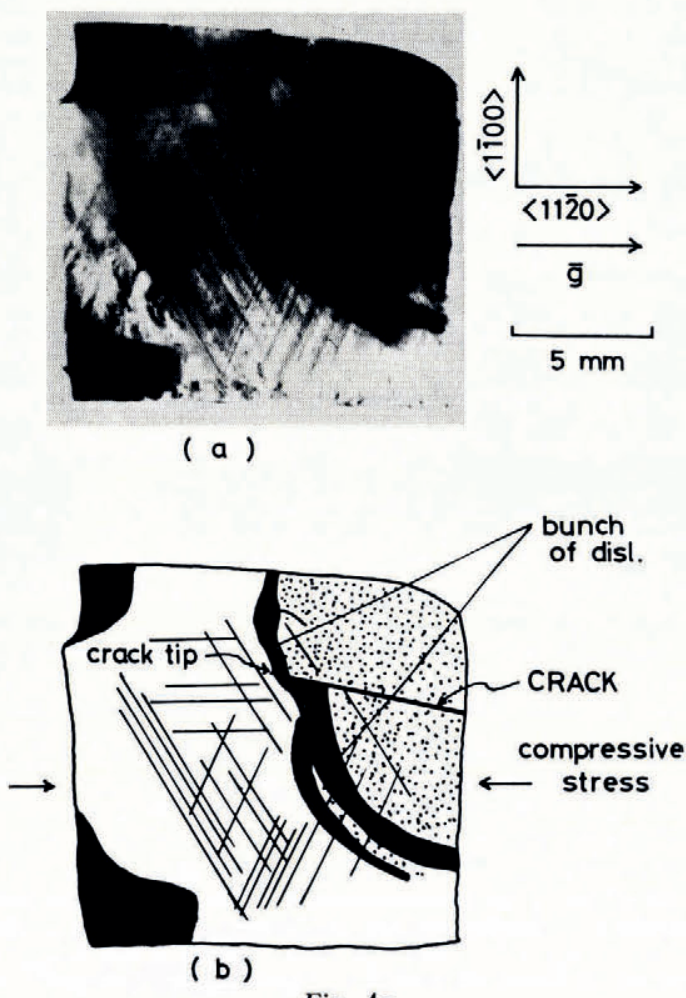

Fig. AI.

(a) An X-ray diffraction topograph showing the two types of dislocation image which appear with the onset of cracking.

(b) A diagram showing the features which appear in $(a)$.

The method for estimating the plastic surface energy $\gamma_{\mathrm{p}}$, or the energy needed for the formation of secondary disiocations around the crack must be different from that developed by Orowan $\left[{ }^{\mathrm{e}} \mathrm{I} 95^{2}\right]$ who only considered the stress concentration at the crack tip. $\gamma_{\mathrm{p}}$ should be proportional to the number of dislocations per unit area of the crack surface formed during deformation. This dislocation density increases with increasing velocity of dislocations $V_{\mathrm{d}}$ and decreasing velocity of crack propagation $V_{\mathrm{c}}$ under applied stress. Then, the equation

$$
\gamma_{\mathrm{p}}=B_{0} V_{\mathrm{d}} / V_{\mathrm{c}}
$$

can be assumed to hold, with $B_{0}$ as a constant. The velocity of crack propagation $V_{\mathrm{c}}$ is not temperature sensitive but stress sensitive. However, since we are considering the boundary, which should lie in narrow range of stress, $V_{c}$ is taken to be constant over a wide range of temperature. Equation $\left(\mathrm{A}_{\mathrm{I}}\right)$ then can be re-written as

where $B$ is the substitute for $B_{0} / V_{\mathrm{c}}$.

$$
\gamma_{\mathrm{p}}=B V_{\mathrm{d}}
$$




\section{DISGUSSION}

R. W. Whitworth: An important question concerns the lowest temperature at which dislocations can glide in ice. You have set the boundary of the "dislocation creep" region of the map at about half the melting point. What is the lowest temperature at which there is definite evidence for dislocation glide?

A. Higashi: We cannot set the lowest temperature definitely. The dislocation creep region is bordered by the boundary between the lattice diffusion region and boundary diffusion region parallel to the contour of equal deformation rate. How low in the temperature scale this region extends depends upon the border between lattice and grain-boundary diffusion. The position of this border depends upon the value of activation energy of both regions.

D. J. Goodman: You show a regime of dislocation glide with cracking on your deformation map. Variation of the hydrostatic stress will suppress the onset of crack formation, and yet in the extrusion tests of Kuon and Jonas (1973) they observed strain-rates proportional to the stress to a power greater than three. In such a test the hydrostatic component must be high, and cracks will not open. Please could you comment on how your deformation map will change with a change of pressure, and how you might include this in your constitutive equation?

Higashi: I appreciate the results of extrusion tests mentioned in a sense that $\epsilon \propto t^{5}$. It is sometimes dangerous to include results which were carried out by different experimental methods. I would like to remark that our map has been constructed for the experimental condition of uniaxial compressive or tension tests (Kuon and Jonas, 1973). We are now experimenting with the effects of hydrostatic pressure.

\section{REFERENCE}

Kuon, L. G., and Jonas, J. J. 1973. Effect of strain rate and temperature on the microstructure of polycrystalline ice. (In Whalley, E., and others, ed. Physics and chemistry of ice: papers presented at the Symposium on the Physics and Chemistry of Ice, held in Ottawa, Canada, $14^{-18}$ August 1972. Edited by E. Whalley, S. F. Jones, L. W. Gold. Ottawa, Royal Society of Canada, p. $370-76$.) 